\title{
The Challenges of Providing Renal Replacement Therapy in Decompensated Liver Cirrhosis
}

\author{
Thomas A. Gonwa Hani M. Wadei \\ Department of Transplantation, Mayo Clinic in Florida, Jacksonville, Fla., USA
}

\section{Key Words}

Renal replacement therapy $\cdot$ Renal failure $\cdot$ Liver cirrhosis

\begin{abstract}
Development of renal failure requiring renal replacement therapy (RRT) in the cirrhotic patient is a devastating complication. Survival without RRT is less than $10 \%$ on average at 6 months. However, it is now appreciated that all renal failure in this group of patients is not due solely to hepatorenal syndrome, and the cause of the renal failure affects the prognosis. This paper reviews the prognosis depending on cause and points out the difficulty in making the correct diagnosis. Provision of RRT is difficult in this group of patients due to hypotension and coagulopathy which is highly prevalent. Survival with RRT is still poor with only $30-60 \%$ of patients surviving to liver transplant. Provision of RRT should be offered as a bridge to patients awaiting liver transplant or those undergoing liver transplant evaluation. Provision of long-term RRT is usually not indicated in other cirrhotic patients who develop a need for RRT except as a trial to see if renal function will return. The decision between intermittent hemodialysis or continuous renal replacement therapy (CRRT) is usually based on the clinical characteristics of the patient. Neither has been demonstrated to be superior to
\end{abstract}

the other, although CRRT may be better tolerated in the unstable patient. CRRT is clearly indicated in cases of fulminant hepatic failure as it does not raise intracranial pressure. Provision of intraoperative CRRT during liver transplant may be indicated to help control volume and electrolytes in those patients presenting for liver transplant with renal failure. Newer extracorporeal support systems, such as extracorporeal albumin dialysis (MARS) and fractional plasma separation and adsorption with hemodialysis (Prometheus), have recently been developed to provide both renal and liver support in this group of patients. These are still considered experimental, although the MARS system has been utilized to treat patients with hepatorenal syndrome, and is available outside the United States.

Copyright $\odot 2012$ S. Karger AG, Basel

Patients who have developed cirrhosis regardless of the cause are at high risk for developing renal dysfunction. The development of cirrhosis leads to renal physiologic changes which are present to varying degrees in all patients with cirrhosis [1-3]. Patients may move along a spectrum from sodium retention to diuretic resistant ascites, and finally to hepatorenal syndrome and the potential need for renal replacement therapy (RRT). The

\section{KARGER}

Fax +4161306 1234 E-Mail karger@karger.ch www.karger.com
(C) 2012 S. Karger AG, Basel 0253-5068/12/0333-0144\$38.00/0

Accessible online at: www.karger.com/bpu
Thomas A. Gonwa, MD, FASN

Mayo Clinic Transplant Center

4500 San Pablo Road

Jacksonville, FL 32224 (USA)

Tel. +1 904956 3360,E-Mail gonwa.thomas@mayo.edu 
nephrologist should be involved in all these stages, not only for management, but also for treatment. The development of acute kidney injury (AKI) is a devastating complication for the cirrhotic patient. A retrospective study from Pittsburgh demonstrated that the mortality rate of cirrhotic patients who developed AKI and who did not get transplanted was $86 \%$ [4]. A more recent study examined the impact of AKI on cirrhotic patients admitted to the intensive care unit and found little change in 10 years [5]. Cholongitas et al. [6] examined 312 cirrhotic patients admitted to the intensive care unit, 128 with AKI and 184 without. Mortality was significantly higher for patients with AKI compared to those without (91 vs. $47 \%$ ). These were patients not transplanted. The same group also looked at the RIFLE classification of AKI in these patients and found it to be useful in predicting mortality. In all these studies, the development of AKI was almost uniformly fatal without progression to liver transplant. However, other recent studies have examined the causes of AKI in cirrhotic patients and the mortality more specifically according to the etiology of the AKI.

The cause of AKI in cirrhotic patients is often thought to be hepatorenal syndrome (HRS). When this diagnosis is given, further care (in the absence of transplantation) is often felt to be futile. However, not all causes of AKI are due to HRS. Wadei et al. [7] performed percutaneous renal biopsies on 44 patients with renal dysfunction who were awaiting liver transplant. The biopsies were done in order to determine if the patient needed a combined liver kidney transplant or a liver transplant alone. Surprisingly, only 24 of 44 of the patients had findings that were compatible with either HRS or acute tubular necrosis. These studies have now been extended to almost 100 patients with similar findings. The liver group from Barcelona has studied renal failure in cirrhosis extensively. A recent paper from their group has examined the prognosis of patients with cirrhosis who develop AKI depending on the etiology of the AKI [8]. They examined the results in 463 consecutive patients who developed renal failure as defined as a serum creatinine greater than $1.5 \mathrm{mg} / \mathrm{dl}$ on two consecutive determinations. They classified the cause of renal failure based on clinical and laboratory values as renal failure associated with infections (213 cases, 46\%), hypovolemia-associated renal failure (149 patients, 32\%), HRS (60 patients, 13\%), and parenchymal nephropathy (41 patients, 9\%). The 3-month probability of survival was markedly different depending on the etiology of the renal failure: $73 \%$ for parenchymal renal failure, $46 \%$ for hypovolemia-associ- ated renal failure, 31\% for renal failure associated with infections, and only $15 \%$ for patients with HRS. These studies were done in patients who did not go on to liver transplant.

With this background in mind, one can realize that one of the first questions that needs to be addressed when evaluating cirrhotic patients with renal failure is which ones should receive RRT. The indications for RRT in these patients are not different from those for other patients with AKI, i.e. volume issues, control of acidosis, uremic complications, and electrolyte disorders such as hyperkalemia. At least one study cited that the most common cause for RRT initiation was volume overload [9]. However, given the dismal prognosis in these patients, most clinicians reserve RRT for one of two reasons. The first is for those patients who are considered candidates for orthotopic liver transplant (OLT) or who are being evaluated for OLT. Survival following OLT in these patients is good, although less than that in patients who do not have renal failure that undergo liver transplant whether as liver transplant alone or as combined liver kidney transplant $[10,11]$. The second type of patient is more problematic, i.e. the patient with AKI who might recover renal function and is not a candidate for liver transplantation. This type of patient usually develops acute tubular necrosis and not HRS, most commonly due to infection or hypovolemia. Such patients are often difficult to separate from those with HRS, and it is reasonable to consider a short course of RRT while the patient's course is clarified.

Once it is decided to offer RRT to these patients, the prognosis is still guarded. An early study from Pittsburgh reported that that only 7 of 16 patients on RRT prior to OLT survived to transplant [4]. An analysis of the UNOS waiting list demonstrated that OLT candidates who were on dialysis had a 6-month survival of only 58\% [12]. A more recent study confirmed these results. Wong et al. [9] studied 102 patients awaiting OLT who were receiving RRT for AKI prior to liver transplant. Survival to transplant occurred in only $33 \%$ of the patients and there was no difference between patients receiving either intermittent hemodialysis (IHD) or continuous renal replacement therapy (CRRT). Part of this is due to the underlying liver disease and part is due to the difficulty in providing RRT to this group of patients who often suffer from hypotension (due to increased shunting), coagulopathy, and thrombocytopenia. Early studies demonstrated that initiation of RRT in cirrhotic patients is associated with increased mortality due in part to the increased risk of hemorrhage and hypotension $[13,14]$. Because of these 
complications, long-term RRT is usually not offered to patients not in the above two categories.

The choice of RRT modality is determined by the patient's condition. CRRT may be better tolerated than IHD as evidenced by improved cardiovascular stability, more gradual correction of hyponatremia (necessary to avoid central pontine myelinolysis) and less fluctuation in intracranial pressure [15-18]. Furthermore, CRRT has the potential advantage of removing inflammatory cytokines such as TNF- $\alpha$ and IL-6, which have been implicated in the development of AKI and HRS as well as the exacerbation of hepatic injury $[19,20]$. Despite these presumed advantages, there have been no controlled trials which demonstrate that either modality is superior in the routine treatment of the cirrhotic patient. However, all comparative studies have pointed out that the populations treated were not comparable and none have been randomized $[9,21,22]$. Therefore, the choice of treatment modality should be tailored to the patient's condition as dictated by hemodynamic stability and severity of illness. One clear indication for CRRT is fulminant hepatic failure. Increased intracranial pressure is the most common cause of death in these patients. Furthermore, increased intracranial pressure can rise during liver transplantation [23]. Increased intracranial pressure rises during IHD and is stable or falls with CRRT $[15,24]$. Therefore, all patients with fulminant hepatic failure should be treated with CRRT.

Eventually, some of the cirrhotic patients requiring RRT may come to OLT. Adverse intraoperative hemodynamic events are not uncommon during the liver transplant surgery. Cross clamping of the inferior vena cava and portal vein during hepatectomy (the anhepatic phase) reduces the venous return and the cardiac output by $40-$ $50 \%$. An extracorporeal circuit (venovenous bypass) can be used to return blood from the infrahepatic inferior vena cava and from the splanchnic circulation to the right side of the heart which limits the fall in cardiac output by $20-30 \%$. The piggyback technique can also be used in lieu of venovenous bypass where the inferior vena cava is side clamped during the surgery, allowing venous return from the lower body to the heart with limited hemodynamic instability. Following completion of the portal anastomosis, portal unclamping results in large amounts of desaturated blood, potassium, and lactic acid entering the main circulation inducing hypotension, hyperkalemia, and metabolic acidosis, which is described as the 'postreperfusion syndrome'. These changes are attenuated, but not completely abrogated, using the piggyback technique. In addition, a large amount of blood or fresh- frozen plasma transfusion is not uncommon during the surgery, which might aggravate any underlying myocardial dysfunction, induce hypotension, and worsen hyperkalemia due to the increased potassium load, especially in blood products with increased shelf life. For all these reasons, fatal intraoperative ventricular fibrillation from hyperkalemia has been reported during OLT.

A retrospective study that included 1,124 OLT patients identified factors associated with hyperkalemia at three different time points surrounding the procedure: $2 \mathrm{~h}$ prior to reperfusion of the allograft, the first $15 \mathrm{~min}$ after reperfusion, and at a late period $1 \mathrm{~h}$ after reperfusion until the end of the case. The pretransplant serum potassium level directly correlated with hyperkalemia at all three time periods. Interestingly, even with normal serum potassium levels, the risk of hyperkalemia increased by up to 7 - and 35 -fold in patients with pretransplant serum potassium of $4-4.5 \mathrm{mEq} / \mathrm{l}$ and $\geq 4.5 \mathrm{mEq} / \mathrm{l}$, respectively. In the first time period, transfusing $>5$ units of red blood cells added to this risk. In the second time period, hyperkalemia was more likely to occur when the allograft obtained from a DCD (donation after cardiac death) donor. Risk factors in the later period included: intraoperative urine output $<500 \mathrm{ml}$, use of venovenous bypass, warm ischemia time $>50 \mathrm{~min}$, and prolonged donor hospital stay ( $>5$ days) [25]. In addition to intraoperative RRT, treatment of hyperkalemia includes administration of insulin-glucose and washing of blood-banked products using cell salvage equipment [26].

In the setting of preoperative or intraoperative renal dysfunction, the risk of intraoperative complications is increased and intraoperative dialysis has been advocated in these settings. Townsend et al. [27] described their experience with intraoperative CRRT. Overall, intraoperative CRRT was used in 41 patients (6.4\%) at their center. Indications for the procedure were preoperative CRRT in almost $50 \%$ of the cases and hyperkalemia, dysnatremia, and metabolic acidosis in the rest of the group. Despite the presence of elevated INR in all the patients, filter circuit clotting occurred in $40 \%$ of the cases. However, heparin or regional citrate anticoagulation was not used except in 3 patients for fear of bleeding diathesis. Nevertheless, CRRT was administered for almost $50 \%$ of the operative time and filter clotting did not affect the duration of CRRT.

This study demonstrates that intraoperative CRRT is feasible and is useful in providing negative or even fluid balance despite a large number of blood transfusions in this cohort [27]. Although it is not clear from the study findings, presumptively intra-operative CRRT was also 
beneficial in managing hyperkalemia and metabolic acidosis, both of which are common during liver transplantation surgery. Further studies are needed on this technique. At our center, we have performed intraoperative CRRT in over 100 patients with good results and few complications. We are in the process of analyzing the results to better define the indications and the best technique.

In addition to IHD and CRRT, there are several other extracorporeal techniques which have been put forward for treatment of both liver and renal failure in cirrhotic patients. These have been recently reviewed by Cerda et al. [28]. These systems consist of membranes and adsorbent-based systems to provide detoxification and dialytic support as well as cell-based systems to provide the excretory, synthetic, and metabolic functions of the liver. Although not classified as RRT, these latter systems can be thought of as liver replacement therapy.

The first category of systems employed in treatment of liver failure consisted of hemoperfusion, hemodiabsorption, therapeutic plasma exchange, plasmapheresis, plasma filtration absorption, and selective plasma filtration therapy (SEPET). None of these techniques have demonstrated a survival advantage as of yet. SEPET is utilized in line with a standard dialysis machine and has been approved for a phase I trial by the FDA. These are all reviewed in the above-mentioned paper. More perti- nent to this discussion are two systems: MARS (molecular adsorbent recirculation system, available outside the United States) and the Prometheus system. The MARS system is designed to remove albumin-bound toxins by albumin dialysis as well as providing standard CRRT. The albumin dialysate is then regenerated utilizing an anion exchange resin and active charcoal adsorption. MARS has been utilized in treatment of HRS and was shown to be superior to CRRT in terms of patient survival and to improve hemodynamics and urine output $[29,30]$. However, no large-scale trial has been carried out and more recent studies (6 patients) in patients with type I HRS not responding to vasoconstrictor therapy found no improvement following MARS therapy in terms of systemic hemodynamics. They and others concluded that this therapy may only be effective as a bridge to transplant [31, 32]. Prometheus employs fractional plasma separation, and adsorption with hemodialysis could be utilized to treat liver failure patients who have a need for RRT; however, it has not yet been studied in this group of patients. It and the cell-based systems have not been studied in cirrhotic patients with renal dysfunction, but have been utilized (mainly) in patients with hepatic failure. In summary, although these therapies may serve to bridge patients to liver transplant, controlled studies are needed. Until then, these therapies should be considered experimental.

\section{References}

1 Davis CL, Gonwa TA, Wilkinson AH: Pathophysiology of renal disease associated with liver disorders: implications for liver transplantation. Part I. Liver Transpl 2002;8:91109.

$\checkmark 2$ Gines P, Cardenas A, Arroyo V, Rodes J: Management of cirrhosis and ascites. N Engl J Med 2004;350:1646-1654.

$\checkmark 3$ Wadei HM, Mai ML, Ahsan N, Gonwa TA: Hepatorenal syndrome: pathophysiology and management. Clin J Am Soc Nephrol 2006;1:1066-1079.

-4 Fraley DS, Burr R, Bernardini J, Angus D, Kramer DJ, Johnson JP: Impact of acute renal failure on mortality in end-stage liver disease with or without transplantation. Kidney Int 1998;54:518-524.

-5 Cholongitas E, Calvaruso V, Senzolo M, Patch D, Shaw S, O’Beirne J, Burroughs AK: RIFLE classification as predictive factor of mortality in patients with cirrhosis admitted to intensive care unit. J Gastroenterol Hepatol 2009;24:1639-1647.
6 Cholongitas E, Senzolo M, Patch D, Shaw S, O’Beirne J, Burroughs AK: Cirrhotics admitted to intensive care unit: the impact of acute renal failure on mortality. Eur J Gastroenterol Hepatol 2009;21:744-750.

7 Wadei HM, Geiger XJ, Cortese C, Mai ML, Kramer DJ, Rosser BG, Keaveny AP, Willingham DL, Ahsan N, Gonwa TA: Kidney allocation to liver transplant candidates with renal failure of undetermined etiology: role of percutaneous renal biopsy. Am J Transplant 2008;8:2618-2626.

8 Martin-Llahi M, Guevara M, Torre A, Fagundes C, Restuccia T, Gilabert R, Sola E, Pereira G, Marinelli M, Pavesi M, Fernandez J, Rodes J, Arroyo V, Gines P: Prognostic importance of the cause of renal failure in patients with cirrhosis. Gastroenterology 2011; 140:488-496, e484.

$\checkmark 9$ Wong LP, Blackley MP, Andreoni KA, Chin H, Falk RJ, Klemmer PJ: Survival of liver transplant candidates with acute renal failure receiving renal replacement therapy. Kidney Int 2005;68:362-370.
10 Jeyarajah DR, Gonwa TA, McBride M, Testa G, Abbasoglu O, Husberg BS, Levy MF, Goldstein RM, Klintmalm GB: Hepatorenal syndrome: combined liver kidney transplants versus isolated liver transplant. Transplantation 1997;64:1760-1765.

11 Gonwa TA, McBride MA, Anderson K, Mai ML, Wadei H, Ahsan N: Continued influence of preoperative renal function on outcome of orthotopic liver transplant (OLTX) in the US: where will MELD lead us? Am J Transplant 2006;6:2651-2659.

12 Davis CL, Feng S, Sung R, Wong F, Goodrich NP, Melton LB, Reddy KR, Guidinger MK, Wilkinson A, Lake J: Simultaneous liverkidney transplantation: evaluation to decision making. Am J Transplant 2007;7:17021709.

13 Ellis D, Avner ED: Renal failure and dialysis therapy in children with hepatic failure in the perioperative period of orthotopic liver transplantation. Clin Nephrol 1986;25:295303. 
14 Wilkinson SP, Weston MJ, Parsons V, Williams R: Dialysis in the treatment of renal failure in patients with liver disease. Clin Nephrol 1977;8:287-292.

15 Davenport A: Renal replacement therapy in the patient with acute brain injury. Am J Kidney Dis 2001;37:457-466.

-16 Davenport A, Bouman C, Kirpalani A, Skippen P, Tolwani A, Mehta RL, Palevsky PM: Delivery of renal replacement therapy in acute kidney injury: what are the key issues? Clin J Am Soc Nephrol 2008;3:869-875.

$\checkmark 17$ Davenport A, Will EJ, Davidson AM: Improved cardiovascular stability during continuous modes of renal replacement therapy in critically ill patients with acute hepatic and renal failure. Crit Care Med 1993;21: 328-338.

18 Davenport A, Will EJ, Davison AM: Effect of renal replacement therapy on patients with combined acute renal and fulminant hepatic failure. Kidney Int Suppl 1993;41:S245-S251.

19 De Vriese AS, Colardyn FA, Philippe JJ, Vanholder RC, De Sutter JH, Lameire NH: Cytokine removal during continuous hemofiltration in septic patients. J Am Soc Nephrol 1999;10:846-853.

-20 Navasa M, Follo A, Filella X, Jimenez W, Francitorra A, Planas R, Rimola A, Arroyo V, Rodes J: Tumor necrosis factor and interleukin- 6 in spontaneous bacterial peritonitis in cirrhosis: relationship with the development of renal impairment and mortality. Hepatology 1998;27:1227-1232.
21 Gonwa TA, Mai ML, Melton LB, Hays SR, Goldstein RM, Levy MF, Klintmalm GB: Renal replacement therapy and orthotopic liver transplantation: the role of continuous venovenous hemodialysis. Transplantation 2001; 71:1424-1428.

-22 Witzke O, Baumann M, Patschan D, Patschan S, Mitchell A, Treichel U, Gerken G, Philipp T, Kribben A: Which patients benefit from hemodialysis therapy in hepatorenal syndrome? J Gastroenterol Hepatol 2004;19:1369-1373.

23 Detry O, Arkadopoulos N, Ting P, Kahaku E, Margulies J, Arnaout W, Colquhoun SD, Rozga J, Demetriou AA: Intracranial pressure during liver transplantation for fulminant hepatic failure. Transplantation 1999;67:767-770.

24 Davenport A, Will EJ, Davison AM, Swindells S, Cohen AT, Miloszewski KJ, Losowsky MS: Changes in intracranial pressure during haemofiltration in oliguric patients with grade IV hepatic encephalopathy. Nephron 1989;53:142-146.

25 Xia VW, Ghobrial RM, Du B, Chen T, Hu K-Q, Hiatt JR, Busuttil RW, Steadman RH: Predictors of hyperkalemia in the prereperfusion, early postreperfusion, and late postreperfusion periods during adult liver transplantation. Anesth Analg 2007;105: 780-785.

26 De Wolf A, Frenette L, Kang Y, Tang C: Insulin decreases the serum potassium concentration during the anhepatic stage of liver transplantation. Anesthesiology 1993;78: $677-682$.
27 Townsend DR, Bagshaw SM, Jacka MJ, Bigam D, Cave D, Gibney RT: Intraoperative renal support during liver transplantation. Liver Transpl 2009;15:73-78.

28 Cerda J, Tolwani A, Gibney N, Tiranathanagul K: Renal replacement therapy in special settings: extracorporeal support devices in liver failure. Semin Dial 2011;24:197-202.

29 Mitzner SR, Klammt S, Peszynski P, Hickstein H, Korten G, Stange J, Schmidt R: Improvement of multiple organ functions in hepatorenal syndrome during albumin dialysis with the molecular adsorbent recirculating system. Ther Apher 2001;5:417-422.

30 Mitzner SR, Stange J, Klammt S, Risler T, Erley CM, Bader BD, Berger ED, Lauchart W, Peszynski P, Freytag J, Hickstein H, Loock J, Lohr JM, Liebe S, Emmrich J, Korten G, Schmidt R: Improvement of hepatorenal syndrome with extracorporeal albumin dialysis MARS: results of a prospective, randomized, controlled clinical trial. Liver Transpl 2000;6:277-286.

$>31$ Khuroo MS, Farahat KL: Molecular adsorbent recirculating system for acute and acute-on-chronic liver failure: a meta-analysis. Liver Transpl 2004;10:1099-1106.

32 Wong F, Raina N, Richardson R: Molecular adsorbent recirculating system is ineffective in the management of type 1 hepatorenal syndrome in patients with cirrhosis with ascites who have failed vasoconstrictor treatment. Gut 2010;59:381-386. 